
3 Research Square
Preprints are preliminary reports that have not undergone peer review.
They should not be considered conclusive, used to inform clinical practice, or referenced by the media as validated information.

\title{
Risk factors associated with echinococcosis in Chinese general population: a meta-analysis and systematic review
}

\author{
tiantian zhang \\ Qinghai University Medical College \\ Bin Li \\ Qinghai Medical College: Qinghai University Medical College \\ Yuying Liu \\ Qinghai Medical College: Qinghai University Medical College \\ Shou Liu ( $\sim$ liushou2004@aliyun.com ) \\ Qinghai University
}

\section{Research}

Keywords: Echinococcosis, Risk factor, Human, Meta-analysis

Posted Date: May 25th, 2021

DOI: https://doi.org/10.21203/rs.3.rs-549342/v1

License: (c) (i) This work is licensed under a Creative Commons Attribution 4.0 International License. Read Full License 


\section{Abstract \\ Background}

Echinococcosis is a severe zoonotic disease that imposes a substantial burden on human life. Numerous studies on echinococcosis have involved a variety of risk factors, and it is difficult to evaluate the key risk factors. The objectives of this meta-analysis are to summarize available data on the prevalence of human echinococcosis and identify the key risk factors for echinococcosis.

\section{Methods}

Relevant studies were comprehensively searched in the PubMed, EMBASE, Web of Science, Cochrane, Chinese National Knowledge Infrastructure (CNKI), Chongqing VIP Information (VIP), Wanfang and SinoMed databases from database inception until August 22, 2020. A random-effects model was used to estimate the pooled odds ratio (OR) and 95\% confidence interval (CI) by integrating the OR values of each risk factor. The $\mathrm{I}^{2}$ and Q statistics were calculated to evaluate the heterogeneity, and potential sources of heterogeneity were identified using sensitivity analysis and subgroup analysis. Publication bias was estimated by funnel plots and Egger's test.

\section{Results}

A total of 1026 studies were identified through the database search, of which 26 were eligible for this meta-analysis. In total, 23 and 9 of the 26 studies were cystic echinococcosis (CE) and alveolar echinococcosis (AE) studies, respectively (6 papers included both AE and CE). The pooled prevalence of echinococcosis was 5.52\% (95\% Cl: 5.47\%-5.58\%). Ethnicity (OR=2.93, 95\% Cl: $1.81-4.75$; $\left.\mathrm{I}^{2}=0\right)$, being a herder $(\mathrm{OR}=2.66$, $\left.95 \% \mathrm{Cl} 95 \% \mathrm{Cl}: 2.25-3.14 ; \mathrm{I}^{2}=8 \%\right)$, not washing hands before meals $\left(\mathrm{OR}=2.40,95 \% \mathrm{Cl}: 1.34-4.28 ; \mathrm{I}^{2}=82.8 \%\right)$ and being female $(\mathrm{OR}=1.45$, 95\% Cl: $\left.1.26-1.66 ; I^{2}=33.9 \%\right)$ were risk factors for AE. The top five risk factors for CE were ethnicity $\left(\mathrm{OR}=3.18,95 \% \mathrm{Cl}: 1.55-6.52 ; \mathrm{I}^{2}=79.2 \%\right)$, nomadism $\left(\mathrm{OR}=2.71,95 \% \mathrm{Cl}: 1.65-4.47 ; \mathrm{I}^{2}=55.8 \%\right)$, drinking nonboiled water $\left(\mathrm{OR}=2.47,95 \% \mathrm{Cl}: 1.36-4.47 ; \mathrm{I}^{2}=85.7\right)$, feeding viscera to dogs $\left(\mathrm{OR}=2.35,95 \% \mathrm{Cl}: 1.89-2.91 ; \mathrm{I}^{2}=21.5 \%\right)$, and being a herder $\left(\mathrm{OR}=2.19,95 \% \mathrm{Cl}: 1.67-2.86 ; \mathrm{I}^{2}=85.1 \%\right)$. The study design-specific subgroup analysis showed that the heterogeneity of CE risk factors decreased to varying degrees.

\section{Conclusions}

Specific characteristics (i.e., ethnicity and herder status) and behaviors (i.e., not washing hands before meals and feeding viscera to dogs ) are possible risk factors for echinococcosis. This study provided remarkable insight for future prevention and control of echinococcosis.

\section{Introduction}

Echinococcosis is widely known as a zoonotic and natural focal disease; it occurs as a result of accidental ingestion of the larval stage of Echinococcus granulosus (E. granulosus) or Echinococcus multilocularis (E. multilocularis) and is classified into cystic echinococcosis (CE) and alveolar echinococcosis (AE)[1]. The annual numbers of new cases of CE and AE were estimated to be 188,000 and 18,200, respectively, leading to a total of 184,000 and 666,000 disability-adjusted life years (DALYs)[2]. The higher mortality rate of AE than of CE is one of the major reasons for AE's greater global burden[3]. AE is also known as "worm cancer"[4].

Echinococcus parasites can inhabit any part of the human body, mainly the liver, lung, brain and abdomen. Once the parasite attaches to the human body, it will be followed by deteriorating health conditions. CE is endemic in pastoral areas around the world, where the infection is often maintained by herders feeding viscera from infected ruminants to dogs. In contrast, human AE infection is usually associated with contact with wild animals, such as hunting foxes[5]. Therefore, compared to those of E. granulosus, the potential risk factors for $E$. multilocularis are more complex because its life cycle involves various wild animals as final hosts and a large number of small mammals (mostly rodents) as intermediate hosts[6].

To date, many studies on the risk factors for echinococcosis have been performed, with each study focusing on certain points. The geographical distribution and prevalence of echinococcosis vary from region to region and are mainly influenced by biological factors and abiotic factors. Biological factors include species, transmission mechanism, density and prevalence among definitive hosts[3]. Abiotic factors include environmental factors, socioeconomic factors and behavioral factors. A study[7] on environmental and socioeconomic risk factors for CE in western China showed that the grassland area ratio positively correlated with the prevalence of human CE and that gross domestic product and land surface temperature (spring) were negative independent variables. Wang Qian[8] reported that fox skin ownership, not preventing flies from landing on food, using open streams as drinking water sources and playing with dogs were statistically significant

Page 2/15 
behavior risk factors for AE. It is difficult to identify the main high-risk factors for echinococcosis because of differences in the study group, type of echinococcosis and study region among studies. Therefore, the present meta-analysis aimed to pool diversification studies and analyze the main risk factors for $\mathrm{AE}$ and $\mathrm{CE}$.

\section{Material And Method Search strategy}

We followed the Preferred Reporting Items for Systematic Reviews and Meta-Analyses guidelines to perform the literature search. Two researchers (T.T.Z. and B.L.) independently searched for relevant articles published in four English (PubMed, Embase, Web of Science, and Cochrane) and four Chinese (China National Knowledge Infrastructure, China Science and Technology Journal Database, Wanfang Data and SinoMed) databases from their inception to August 22, 2020. The search terms were [("echinococcosis" OR "echinococcoses" OR "echinococcus infection" OR "hydatidosis" OR "hydatidoses" OR "hydatid cyst" OR "hydatid disease" OR "echinococcus granulosus infection") AND ("risk factor" OR "population at risk" OR "homo sapiens" OR "man" OR "human") AND ("People's Republic of China” OR “Chinese” OR "China")]. In addition, the references of reviews and meta-analyses were manually screened to identify additional potential studies.

\section{Eligibility criteria}

Studies were eligible if they met the following inclusion criteria: (1) the research was conducted among Chinese residents, (2) diagnoses of AE and CE were based on a combination of serological and ultrasonic detection, and (3) the odds ratio (OR) and its $95 \%$ confidence interval (CI) could be obtained directly or calculated from the study.

Studies were excluded if (1) the publications were neither in Chinese nor in English; (2) the sample size was 30 or less[9]; (3) no risk factors were reported; (4) if there were several articles based on data from one study sample, only the article with the most comprehensive results was included; and (5) low-quality literature based on the overall Newcastle-Ottawa Scale (NOS) or Agency for Healthcare Research and Quality (AHRQ) score.

\section{Quality assessment}

Two authors (T.T.Z. and B.L.) independently assessed the quality of the included studies. We employed NOS and AHRQ scores to assess the study quality. The NOS score ranges from $0-8$, and scores of 7-8, 4-6 and 0-3 indicate high, medium and low quality of the included study, respectively[10,11]. The AHRQ score is between 0 and 11 , with scores of $8-11$ indicating high quality and scores of $4-7$ and $0-3$ indicating moderate and low quality, respectively[12]. Any disagreements in the process were resolved by discussion with the third author (S.L).

\section{Data extraction}

Two authors (T.T.Z. and B.L.) independently extracted data and information including the first author of the study, year of publication, region of study, type of echinococcosis (AE or CE), study design, sample size, positive cases, age in years, sex, race/ethnicity, herder status, raising of dogs, kind/number of animal host, hand washing status, and the OR value and its $95 \% \mathrm{Cl}$ or the original data from which the OR could be calculated.

\section{Meta-analysis}

The ORs and their $95 \%$ Cls of the associated factors were pooled using random-effects models if there were at least three studies reporting data on the same factor[13]. The results were also represented using forest plots. The Q test was used to test the level of heterogeneity between studies, and the percentage of total variation in the results due to heterogeneity was assessed based on the $\mathrm{I}^{2}$ statistic. An $\mathrm{I}^{2}<25 \%$, 25-50\%, 50-75\% and 75-100\% represents no, moderate, large and extreme heterogeneity, respectively[14]. In this study, P $₫ 0.05$ and $I^{2} \varangle 50 \%$ were considered to indicate heterogeneity between studies[15]. Sensitivity analysis was performed using the leave-one-out method to evaluate the stability and reliability of the result. In addition, Egger's test[16] and funnel plots were used to test for the presence of publication bias. The prevalence of echinococcosis in epidemic areas was obtained by combining the prevalence in cross-sectional studies.

We employed subgroup analysis to explore the source of heterogeneity on the basis of the study design (case-control study and crosssectional study) and geographic distribution of the studies (Ningxia, Qinghai and Xinjiang). Data were analyzed using the R(4.0.0) package meta[17, 18], and $p<0.05$ was considered statistically significant.

\section{Results}

Study selection 
A total of 1,026 articles were originally identified, and 449 were excluded as duplicates. A total of 577 studies were screened, and 26[8, 19-43] of them were eligible and included in this meta-analysis. The literature selection process is detailed in Figure 1. The basic characteristics of the included studies are shown in Table 1. All 20 cross-sectional studies were of medium quality. Within the case-control studies, there were three medium-quality studies and three high-quality studies (Table. 1). There were no cohort studies involved in our analysis.

Overall, the included studies covered 690,322 samples ( $A E=54,338, C E=635,984)$, of which $38,358(A E=1,588, C E=36,770)$ were positive based on the combined diagnosis of ultrasound and serological methods. The included studies were from the Tibetan Autonomous Region ( $n=1)$, Qinghai Province $(n=4)$, Western China $(n=2)$, Yunnan Province $(n=1)$, Gansu Province $(n=3)$, Xinjiang Province ( $n=5)$, Ningxia Province $(n=5)$, Sichuan Province $(n=3)$, and the Tibetan Plateau $(n=2)$. Three studies reported only on AE-infected patients, seventeen reported only on CEinfected patients, and six studies reported on both AE- and CE-infected patients.

Ultimately, thirteen potential risk factors reported in more than three studies were included in the meta-analysis, namely, sex, ethnicity, dog ownership, touching fox skin, lack of washing hands before meals, playing with dogs, herder status, feeding viscera to dogs, drinking nonboiled water, presence of stray dogs, number of household dogs, nomadism and eating raw vegetables.

Twenty cross-sectional studies reported the prevalence of echinococcosis until August 2020, and the pooled prevalence of echinococcosis in endemic districts was $5.52 \%$ (95\% Cl: $5.47 \%-5.58 \%)$.

Potential risk factors for $A E$

Seven risk factors were recognized among the studies including $A E$, and a meta-analysis was executed on nine cross-sectional studies[8, 25 , $31,32,35,39-41,43]$. The results of the meta-analysis and forest plots are summarized in Table 2 and Figure 2.

Four risk factors were statistically significant. According to the strength of correlation, they were ethnicity (Tibetan/Han) (OR=2.93, $95 \% \mathrm{Cl}$ : 1.81-4.75; $\mathrm{p}<0.001)$, herder status (OR=2.66, 95\% Cl: 2.25-3.14; $\mathrm{p}<0.001)$, not washing hands before meals $(\mathrm{OR}=2.40,95 \% \mathrm{Cl}: 1.34-4.28$; $\mathrm{p}=0.003)$ and sex (female/male) $(\mathrm{OR}=1.45,95 \% \mathrm{Cl}: 1.26-1.66 ; \mathrm{p}<0.001)$.

\section{Potential risk factors for $C E$}

Eleven risk factors were recognized among the CE studies, and a meta-analysis was performed on twenty-three[19-30, 32-42] of the included papers. These papers include six case-control studies[20, 22, 33, 34, 37, 38] and seventeen cross-sectional studies[19, 21, 23-30, 32, 35, 36, 3942]. The results are shown in Table 2 and Figure 3.

All of the risk factors were statistically significant. According to the strength of the correlation, the top three were ethnicity (Tibetan/Han) $(\mathrm{OR}=3.18,95 \% \mathrm{Cl}: 1.55-6.52 ; \mathrm{p}=0.002)$, nomadism $(\mathrm{OR}=2.71,95 \% \mathrm{Cl}: 1.65-4.47 ; \mathrm{p}<0.001)$ and drinking nonboiled water $(\mathrm{OR}=2.47,95 \% \mathrm{Cl}=1.37-$ 4.47; $p=0.003)$.

\section{Sensitivity analysis}

The sensitivity analysis revealed that for most of the risk factors, the results were stable. However, when we removed two studies (P.M. SCHANTZ 2003 and Xianglin Wu 2010) on AE, the heterogeneity of playing with dogs and dog ownership declined markedly, and their corresponding results became statistically significant. Similarly, when we removed the studies of CE He Ye 2019, AiLuo 2014 and Wenting Wu 2018, the heterogeneity of sex, ethnicity and the presence of stray dogs dropped below $50 \%$. More details are shown in Additional file 1.

\section{Publication bias}

The publication bias test was performed for all the risk factors included in this study (see Additional file 1). Based on the results of Egger's test and the funnel chart, the CE risk factors sex, herder status and feeding viscera to dogs exhibited publication bias. Other risk factors had no bias; for instance, the $p$ value of Egger's test for the AE risk factor sex was greater than 0.05 , and the funnel chart was substantially symmetric (Figure 4).

\section{Subgroup analysis}

The study design-specific subgroup analysis was only conducted on CE risk factors because all of the AE articles were cross-sectional studies. The results are shown in Additional file 1. In the case-control studies, two risk factors were identified and were statistically significant: dog ownership (OR=1.35, 95\% Cl: 1.03-1.83; $\mathrm{p}=0.029)$ and feeding viscera to dogs (OR=2.76, 95\% Cl: 2.00-3.83; $\mathrm{p}<0.001)$. In the cross-sectional studies, seven risk factors were identified and were statistically significant. According to the strength of the correlation, the top three were ethnicity (OR=3.71, 95\% Cl: 1.60-8.59; $p=0.002)$, not washing hands before meals $(\mathrm{OR}=2.37,95 \% \mathrm{Cl}: 1.40-4.00 ; \mathrm{p}=0.003)$ and herder status 
$(\mathrm{OR}=2.30,95 \% \mathrm{Cl}: 1.74-3.04 ; \mathrm{p}<0.001)$. The heterogeneity of all the CE risk factors decreased to varying degrees. The results of sensitivity analysis and publication bias are shown in Additional file 1.

In general, the studies had a wide geographical distribution and involved seven provinces in China. The subgroup analysis based on study region was performed for Ningxia, Qinghai and Xinjiang provinces and included 3 risk factors, 2 risk factors and 1 risk factor, respectively. The CE risk factors sex in Xinjiang and drinking nonboiled water in Ningxia had high heterogeneity, and the test of their overall effect was not significant. However, the heterogeneity of other risk factors was considerably low. An additional file shows this in more detail(see Additional file 1). The results of sensitivity analysis and for publication bias are shown in Additional file 1.

\section{Discussion}

The pooled prevalence of echinococcosis was 5.52\% (95\% $\mathrm{Cl}=5.47 \%-5.58 \%)$. However, the prevalence of population surveillance reached $0.41 \%$ in 2017 [44], which is a significant decrease. Having a good understanding of the risk factors for the transmission of echinococcosis helps better control echinococcosis.

This meta-analysis showed that sex, ethnicity, lack of washing hands before meals, herder status and dog ownership were common risk factors for AE and CE. Females are more likely to develop echinococcosis than males. Females undertake housework, such as food preparation and pet care, and they have more opportunities for contact with dogs and sheep[45]. Moreover, females under ultrasonic tests more often than males due to reproductive health, which is called detection signal bias. An experimental study conducted by Blancas Mosqueda M[46] found that parasites may live longer in females due to the potential association between hormones and granulomatous responses, and females are more susceptible to echinococcosis than males. Tibetans have more opportunities to contract echinococcosis because most Tibetans are herders[29], and livestock and sheepdogs are common intermediate hosts of echinococcosis. Tibetans might be a confounding factor since herders contact infected mammals more frequently.

The digestive tract is the main route of human infection because echinococcosis can spread via the ingestion of food, soil, and water contaminated with the feces of infected dogs[47]. Not washing hands before meals and the CE-related risk factors drinking nonboiled water and eating raw vegetables are poor habits that can lead to mistakenly ingesting worm eggs, increasing the risk of disease. This result was consistent with those of previous studies[48, 49].

Nomadism, a lifestyle form involving animal grazing, is a risk factor for CE. The lifestyle of nomads is the opposite of collectivization; nomads live in areas with lower hygiene and economic disadvantage, where they have more exposure to infected dogs and infected foods and a higher probability of getting the infection.

This study included a number of dog-related risks since dogs are the most common host, such as dog ownership, playing with dogs, number of household dogs, feeding viscera to dogs and the presence of stray dogs. Stray dogs easily find and ingest raw offal from infected animals, and their feces is not collected from the environment. These dogs leave the echinococcus eggs behind and thereby expand the range of contamination. Infected domestic dogs carry eggs in their fur or discharge excrement that carries the eggs[50]. All of these factors will increase the chance of human echinococcosis. Furthermore, for many rural families, dogs are less likely to obtain nutritious food, so they hunt small mammals, which are intermediate hosts of echinococcus[51]. This will increase the risk of echinococcosis. On the other hand, many dog owners fed dogs the viscera of livestock, which supports the lifecycle of echinococcus[52]. Dogs, the main participants in transmission, play a key role in prevention and control. In New Zealand (1959-1991) and Tasmania (1964-1996), dogs were systematically dewormed every 45 days[53]. This strategy was extremely successful in the final elimination of CE as a public health problem. It is noteworthy that feeding dogs viscera was mentioned in both cross-sectional studies and case-control studies, and the results were basically consistent.

In the study of Schweiger[54], an increase in the fox population density started in 1985, and after a 10-15 year latency period, the number of human $\mathrm{AE}$ cases underwent a significant increase. A reasonable explanation may be urbanization[55], which has resulted in an increased number of foxes appearing in the living quarters of people. Increased opportunities for people to come into contact with foxes increased the infection risk for the human population. Some previous studies have also shown that exposure to foxes increases the risk of $A E$ infection[45, 56]. However, the risk of touching fox skin was not significant in this study. After sensitivity analysis, $I^{2}$ changed to 0.00 , but the test for an overall effect was still not significant. This might be caused by a lack of data, outdated studies and the poor quality of the literature.

The results of the test for an overall effect of the AE-related risk factors dog ownership and playing with dogs were not statistically significant. After sensitivity analysis, the results became significant. Thus, the studies of Xianglin Wu 2010 and P.M. SCHANTZ 2003 had an excessive influence on the result. The results of the test for an overall effect of the CE-related risk factors sex, herder status and feeding viscera to dogs revealed publication bias. After we conducted subgroup analysis based on study design, the publication bias disappeared, and heterogeneity decreased. For example, as shown in Figure 5, when we excluded the case-control study, the funnel chart became symmetric, and the result of the CE risk factor sex became significant. Therefore, differences in study design may be the source of heterogeneity. However, the region-

Page 5/15 
specific subgroup analysis did not greatly limit heterogeneity. The studies related to the risk of drinking nonboiled water in Ningxia included two case-control studies and a cross-sectional study. The sample size related to the risk factor sex in Xinjiang was smaller than that of the other factors. The different study designs and small sample sizes may explain the high heterogeneity and nonsignificant overall effects. The heterogeneity of the other risk factors was considerably low. It is not clear whether study region was the source of heterogeneity.

Our study has several limitations, most relating to the lack of literature for further analysis. Although we have identified some risk factors for echinococcosis, more factors need to be analyzed, such as environmental factors and economic factors. Some limitations are related to the study design of the included studies. All of these are observational studies (case-control and cross-sectional studies) that have intrinsic limits. For instance, observational studies are prone to selection bias and information bias[57]. In addition, the chronological sequence of exposure and outcome could not be determined in these studies. Moreover, the region of this study was found to be insufficient. Specifically, the study area included in this meta-analysis did not cover all the regions with a high incidence of echinococcosis.

\section{Conclusion}

In summary, the most active factors affecting the prevalence of echinococcosis among residents are dog-related factors, such as dog ownership, playing with dogs, feeding viscera to dogs, number of household dogs and the presence of stray dogs. There were also diet-related factors, such as not washing hands before meals, drinking nonboiled water, and eating raw vegetables, and demographic factors, such as sex and herder status. Prevention of echinococcosis in humans lies in improved personal and environmental hygiene, and echinococcosis in animals can be prevented by monthly artificial pest control[58]. A series of national control measures, including regular dog deworming, public health education and community screening, are in operation[59]. They have been proven to be effective[58, 59]. The focus of current prevention and control work is the major risk factors and implementation of these policies.

\section{Declarations}

\section{Ethics approval and consent to participate}

Not applicable

\section{Consent for publication}

Not applicable

\section{Availability of data and material}

The datasets generated and/or analysed during the current study are available from the corresponding author on reasonable request.

\section{Funding}

The study was supported by the National Natural Science Foundation of China (81860606); the Natural Science Foundation of Qinghai Province(2019-ZJ-906).

\section{Contributors}

Study design: TZ, SL.

Data collection, analysis and interpretation: TZ, BL,YL.

Drafting of the manuscript: TZ, SL.

Approval of the final version for publication: All authors.

\section{Acknowledgements}

Not applicable

\section{Conflict of interest}

All authors declare that there are no conflicts of interest.

\section{References}


1. Brunetti E, Kern P, Vuitton DA. Expert consensus for the diagnosis and treatment of cystic and alveolar echinococcosis in humans. Acta Trop 2010, 114:1-16.

2. Torgerson PR, Devleesschauwer B, Praet N, Speybroeck N, Willingham AL, Kasuga F, Rokni MB, Zhou XN, Fèvre EM, Sripa B, et al. World Health Organization Estimates of the Global and Regional Disease Burden of 11 Foodborne Parasitic Diseases, 2010: A Data Synthesis. PLoS Med 2015, 12:e1001920.

3. Deplazes P, Rinaldi L, Alvarez Rojas CA, Torgerson PR, Harandi MF, Romig T, Antolova D, Schurer JM, Lahmar S, Cringoli G, et al. Global Distribution of Alveolar and Cystic Echinococcosis. Adv Parasitol 2017, 95:315-493.

4. Xiaowei G. The West China Model of Fighting against "worm Cancer". China health 2018:81-82.

5. Ito A, Budke CM. The echinococcoses in Asia: The present situation. Acta Trop 2017, 176:11-21.

6. Eckert J, Thompson RC. Historical Aspects of Echinococcosis. Adv Parasitol 2017, 95:1-64.

7. Huang D, Li RD, Qiu J, Sun XD, Yuan RX, Shi YY, Qu YB, Niu YN. Geographical Environment Factors and Risk Mapping of Human Cystic Echinococcosis in Western China. International Journal of Environmental Research and Public Health $2018,15$.

8. Wang Q, Qiu J, Yang W, Schantz PM, Raoul F, Craig PS, Giraudoux P, Vuitton DA. Socioeconomic and behavior risk factors of human alveolar echinococcosis in Tibetan communities in Sichuan, People's Republic of China. American Journal of Tropical Medicine and Hygiene 2006, 74:856-862.

9. Weber EJ, Hoo ZH. Why sample size estimates? Emerg Med J 2018, 35:755-756.

10. Lo CK, Mertz D, Loeb M. Newcastle-Ottawa Scale: comparing reviewers' to authors' assessments. BMC Med Res Methodo/2014, 14:45.

11. Neal BS, Lack SD, Lankhorst NE, Raye A, Morrissey D, van Middelkoop M. Risk factors for patellofemoral pain: a systematic review and meta-analysis. Br J Sports Med 2019, 53:270-281.

12. Hu J, Dong Y, Chen X, Liu Y, Ma D, Liu X, Zheng R, Mao X, Chen T, He W. Prevalence of suicide attempts among Chinese adolescents: A meta-analysis of cross-sectional studies. Compr Psychiatry 2015, 61:78-89.

13. Wallace BC, Schmid CH, Lau J, Trikalinos TA. Meta-Analyst: software for meta-analysis of binary, continuous and diagnostic data. BMC Med Res Methodol 2009, 9:80.

14. Huedo-Medina TB, Sánchez-Meca J, Marín-Martínez F, Botella J. Assessing heterogeneity in meta-analysis: Q statistic or l² index? Psychological Methods 2006, 11:193-206.

15. Hoaglin DC. Misunderstandings about Q and 'Cochran's Q test' in meta-analysis. Stat Med 2016, 35:485-495.

16. Khalkhali HR, Foroutan M, Khademvatan S, Majidiani H, Aryamand S, Khezri P, Aminpour A. Prevalence of cystic echinococcosis in Iran: a systematic review and meta-analysis. J Helminthol 2018, 92:260-268.

17. Schwarzer G, Carpenter J, Rücker G. Meta-Analysis with R. 2015.

18. Balduzzi S, Rücker G, Schwarzer G. How to perform a meta-analysis with R: a practical tutorial. Evid Based Ment Health 2019, 22:153-160.

19. Zeng XM, Guan YY, Wu WP, Wang LY, Cai HX, Fang Q, Yu SC, Zheng CJ. Analysis of Factors Influencing Cystic Echinococcosis in Northwest Non-Qinghai Tibetan Plateau Regions of China. American Journal of Tropical Medicine and Hygiene 2020, 102:567-573.

20. He W, Wang Q, Huang Y, Yu WJ, Zhang GJ, Liao S, Wang Q, Yang L, Chen F, Li RR, Zhong B. Risk factors of human cystic echinococcosis in Shiqu County Sichuan Province: a case-control study. Chinese Journal of Schistosomiasis Control. 2019, 31:486-490.

21. Li B, Quzhen GS, Xue CZ, Han S, Chen WQ, Yan XL, Li ZJ, Quick ML, Huang Y, Xiao N, et al. Epidemiological survey of echinococcosis in Tibet Autonomous Region of China. Infectious Diseases of Poverty 2019, 8.

22. Wen-Ting W, Wei-Ping W, Ya-Yi G, Shuai H, Chui-Zhao X, Xu W, Bai-Xue L. A case-control study on risk factors of cystic echinococcosis in humans in Tibetan areas. Zhongguo Xue Xi Chong Bing Fang Zhi Za Zhi 2018, 30:161-164.

23. Yuan R, Wu H, Zeng H, Liu P, Xu Q, Gao L, Li Y, Li R, Huang D, Yu C, Sun X. Prevalence of and risk factors for cystic echinococcosis among herding families in five provinces in western China: A crosssectional study. Oncotarget 2017, 8:91568-91576.

24. Li K, Zhang L, Zhang H, Lei Z, Luo H, Mehmood K, Shahzad M, Lan Y, Wang M, Li J. Epidemiological investigation and risk factors of Echinococcus granulosus in yaks (Bos grunniens), Tibetan pigs and Tibetans on Qinghai Tibetan plateau. Acta Trop 2017, 173:147-152.

25. Ye H, Jiaxiang Y. Analysis for epidemiological factors of echinococcosis. China Tropical Medicine 2017, 17:418-420.

26. Li D, Gao Q, Liu J, Feng Y, Ning W, Dong Y, Tao L, Li J, Tian X, Gu J, Xin D. Knowledge, attitude, and practices (KAP) and risk factors analysis related to cystic echinococcosis among residents in Tibetan communities, Xiahe County, Gansu Province, China. Elsevier B.V. 2015, 147.

27. Xinwei Q, Xiaohui F, Kesteren FV, et al. Epidemic status of Echinococcus granulosus and risk factors of human cycstic echinococcosis in Hoboksar Mongolian Autonomous County of Xinjiang. Chinese Journal of Endemiology 2015, 34:56-60.

28. jie YS-, Min L, Tian T, et al. Epidemiological characteristics of human hydatidosis and risk factors in Habahe County $\mathbb{X}$ Xinjiang. DISEASE SURVEILLANCE 2015, 30:485-488.

Page $7 / 15$ 
29. Luo A, Wang H, Li JQ, Wu HS, Yang F, Fang PQ. Epidemic factors and control of hepatic echinococcosis in Qinghai province. J Huazhong Univ Sci Technolog Med Sci 2014, 34:142-145.

30. Bai K, Wang X. Epidemic characteristics and related influencing factors of hydatid disease. China Journal of Pharmaceutical Economics 2013:414-415.

31. Giraudoux P, Raoul F, Pleydell D, Li T, Han X, Qiu J, Xie Y, Wang H, Ito A, Craig PS. Drivers of Echinococcus multilocularis transmission in China: small mammal diversity, landscape or climate? PLoS Neg/ Trop Dis 2013, 7:e2045.

32. Yun-Ling F, Xang-lin W, Li L, et al. INVESTIGATION ON ECHINOCOCCOSIS EPIDEMIOLOGICAL OF FEMALE POPULATION IN THE RURAL AREAS OF NINGXIA. Modern Preventive Medicine 2011, 38:3214-3215,3218.

33. Wang Guizhi. Risk factors analysis of some endemic areas of cystic echinococcosis in northern Xinjiang. Xinjiang Medical University, 2009.(In Chinese with English abstract)

34. Junxia Y, Xiaoqin R. Epidemic status and influencing factors of hydatidosis in Pingchuan district in 2009. CHINESE COMMUNITY DOCTORS 2011, 13:224-224.

35. WuXiang-lin, ZhangMin, LiLi, et al. Hydatid Disease Risk Factor Analysis of the Human the Rural Area of Ningxia . China Medical Herald 2010, 84:1763-1764.

36. Zhongli. An Epidemiology Study on the Cystic Echinococcosis in Xinyuan County. Xinjiang Medical University, 2009.(In Chinese with English abstract)

37. Li L. Study on risk factors of eehinococeosis in Ningxia. Ningxia Medical Journal 2008, 30:133-135.

38. Jv Y, Li L, Tianxi L. Case control study of cystic hydatid disease in high-risk areas of Ningxia. In Proceedings of the Second National Symposium on Zoonoses. Jiangsu Taizhou; 2008:349-353.

39. Yu RY, Sun T, Li Z, Zhang J, Teng J, Liu X, Liu R, Zhao R, Jones MK, Wang Y, et al. Community surveys and risk factor analysis of human alveolar and cystic echinococcosis in Ningxia Hui Autonomous Region, China. Bulletin of the World Health Organization 2006, 84:714-721.

40. Schantz PM, Wang H, Qiu J, Liu FJ, Saito E, Emshoff A, Ito A, Roberts JM, Delker C. Echinococcosis on the Tibetan Plateau: prevalence and risk factors for cystic and alveolar echinococcosis in Tibetan populations in Qinghai Province, China. Parasitology 2003, 127 Suppl:S109120.

41. Qian W, Jia-min Q, Schantz P, et al. Investigation of Risk Factors for Development of Human Hydatidosis Among Households Raising Livestock in Tibetan Areas of Western Sichuan Province. . Chinese Journal of Parasitology and Parasitic Diseases $2001,19$.

42. Xian-hong W, Duo-long H. An Epidemiological Investigation on Hydatid Disease in Gonghe County, Qinghai Province. ENDEMIC DISEASES BULLETIN2001, 16:29-31.

43. Craig PS, Giraudoux P, Shi D, Bartholomot B, Barnish G, Delattre P, Quere JP, Harraga S, Bao G, Wang Y, et al. An epidemiological and ecological study of human alveolar echinococcosis transmission in south Gansu, China. Acta Trop 2000, 77:167-177.

44. Sihui W, Weiping W, Shuai H, Chuizhao X. Analysis of hydatid surveillance results in China from 2016-2017. Journal of Pathogen Biology 2020, 15:924-928.

45. Ping L, Jinhua L, Yin L, et al. The Epidemic Situation and Causative Analysis of Echinococcosis. China Animal Health Inspection 2016, 33:48-51.(In Chinese with English abstract)

46. Blancas Mosqueda M, Herrera Esparza R, Rodríguez Padilla C, Tavizón García JP, Mercado Reyes M, Badillo Almaraz V, Echavarría F, López Saucedo A, Mondragón de la Peña C. Gender as a factor of susceptibility to infection in experimental hydatidosis. Rev Latinoam Microbiol 2007, 49:31-37.

47. Kern P, Menezes da Silva A, Akhan O, Müllhaupt B, Vizcaychipi KA, Budke C, Vuitton DA. The Echinococcoses: Diagnosis, Clinical Management and Burden of Disease. Adv Parasitol 2017, 96:259-369.

48. Acosta-Jamett G, Weitzel T, Boufana B, Adones C, Bahamonde A, Abarca K, Craig PS, Reiter-Owona I. Prevalence and risk factors for echinococcal infection in a rural area of northern Chile: a household-based cross-sectional study. PLoS Negl Trop Dis 2014, 8:e3090.

49. Craig PS, McManus DP, Lightowlers MW, Chabalgoity JA, Garcia HH, Gavidia CM, Gilman RH, Gonzalez AE, Lorca M, Naquira C, et al. Prevention and control of cystic echinococcosis. Lancet Infect Dis 2007, 7:385-394.

50. Tamarozzi F, Deplazes P, Casulli A. Reinventing the Wheel of Echinococcus granulosus sensu lato Transmission to Humans. Trends in Parasitology 2020, 36:427-434.

51. Liu CN, Xu YY, Cadavid-Restrepo AM, Lou ZZ, Yan HB, Li L, Fu BQ, Gray DJ, Clements AA, Barnes TS, et al. Estimating the prevalence of Echinococcus in domestic dogs in highly endemic for echinococcosis. Infect Dis Poverty 2018, 7:77.

52. Laivacuma S, Deksne G, Jokelainen P, Ivanovs A, Zaharova L, Zeltina I, Vỉksna L, Krūmiṇa A. Risk Factors for Human Cystic Echinococcosis in Latvia. Vector Borne Zoonotic Dis 2019, 19:430-433. 
53. Larrieu E, Gavidia CM, Lightowlers MW. Control of cystic echinococcosis: Background and prospects. Zoonoses Public Health 2019, 66:889-899.

54. Schweiger A, Ammann RW, Candinas D, Clavien PA, Eckert J, Gottstein B, Halkic N, Muellhaupt B, Prinz BM, Reichen J, et al. Human alveolar echinococcosis after fox population increase, Switzerland. Emerg Infect Dis 2007, 13:878-882.

55. Wu T, Perrings C, Kinzig A, Collins JP, Minteer BA, Daszak P. Economic growth, urbanization, globalization, and the risks of emerging infectious diseases in China: A review. Ambio 2017, 46:18-29.

56. Bastien M, Vaniscotte A, Combes B, Umhang G, Germain E, Gouley V, Pierlet A, Quintaine T, Forin-Wiart MA, Villena I, et al. High density of fox and cat faeces in kitchen gardens and resulting rodent exposure to Echinococcus multilocularis and Toxoplasma gondii. Folia Parasitol (Praha) 2018, 65.

57. Pandis N. Bias in observational studies. Am J Orthod Dentofacial Orthop 2014, 145:542-543.

58. Moro P, Schantz PM: Echinococcosis: a review. Int J Infect Dis 2009, 13:125-133.

59. Wen H, Vuitton L, Tuxun T, Li J, Vuitton DA, Zhang W, McManus DP. Echinococcosis: Advances in the 21st Century. Clin Microbiol Rev $2019,32$.

\section{Tables}

Table 1 Main characteristics of the included studies. 


\begin{tabular}{|c|c|c|c|c|c|c|c|c|c|}
\hline No. & Author & $\begin{array}{l}\text { Year of } \\
\text { Publication }\end{array}$ & Region & $\begin{array}{l}\text { Type of } \\
\text { Echinococcosis }\end{array}$ & $\begin{array}{l}\text { Study } \\
\text { Design }\end{array}$ & $\begin{array}{l}\text { Sample } \\
\text { Size }\end{array}$ & $\begin{array}{l}\text { Positive } \\
\text { case }\end{array}$ & Risk Factors* & $\begin{array}{l}\text { Quality } \\
\text { score }\end{array}$ \\
\hline 1 & $\begin{array}{l}\text { Manxiang } \\
\text { Zeng }\end{array}$ & 2020 & $\begin{array}{l}\text { Western } \\
\text { China }\end{array}$ & CE & $\begin{array}{l}\text { Cross- } \\
\text { sectional }\end{array}$ & 470400 & 32928 & 11 & 4 \\
\hline 2 & Wei He & 2019 & SiChuan & CE & $\begin{array}{l}\text { Case- } \\
\text { control }\end{array}$ & - & - & $1,11,12$ & 8 \\
\hline 3 & Bin Li & 2019 & Tebit & CE & $\begin{array}{l}\text { Cross- } \\
\text { sectional }\end{array}$ & 80384 & 1371 & 1,7 & 6 \\
\hline 4 & Wenting Wu & 2018 & $\begin{array}{l}\text { Tibetan } \\
\text { plateau }\end{array}$ & CE & $\begin{array}{l}\text { Case- } \\
\text { control }\end{array}$ & 378 & 189 & $3,5,8,10,11$ & 7 \\
\hline 5 & Kun Li & 2017 & Qinghai & CE & $\begin{array}{l}\text { Cross- } \\
\text { sectional }\end{array}$ & 600 & 11 & 1 & 4 \\
\hline 6 & Ruixia Yuan & 2017 & $\begin{array}{l}\text { Western } \\
\text { China }\end{array}$ & CE & $\begin{array}{l}\text { Cross- } \\
\text { sectional }\end{array}$ & 5813 & 90 & $5,8,10,9,13$ & 4 \\
\hline \multirow[t]{2}{*}{7} & \multirow[t]{2}{*}{ Ye He } & \multirow[t]{2}{*}{2017} & \multirow[t]{2}{*}{ Yunnan } & $A E$ & \multirow{2}{*}{$\begin{array}{l}\text { Cross- } \\
\text { sectional }\end{array}$} & \multirow[t]{2}{*}{9460} & \multirow[t]{2}{*}{348} & 1 & \multirow[t]{2}{*}{5} \\
\hline & & & & CE & & & & 1 & \\
\hline 8 & Dan Li & 2015 & Gansu & CE & $\begin{array}{l}\text { Cross- } \\
\text { sectional }\end{array}$ & 972 & 92 & 8,12 & 5 \\
\hline 9 & Shijie Yang & 2015 & Xinjiang & CE & $\begin{array}{l}\text { Cross- } \\
\text { sectional }\end{array}$ & 42356 & 159 & 7 & 5 \\
\hline 10 & Xinwei Qi & 2015 & Xinjiang & CE & $\begin{array}{l}\text { Cross- } \\
\text { sectional }\end{array}$ & 532 & 23 & 1,7 & 4 \\
\hline 11 & AiLuo & 2014 & Qinghai & CE & $\begin{array}{l}\text { Cross- } \\
\text { sectional }\end{array}$ & 23445 & 1048 & $1,2,7$ & 6 \\
\hline 12 & $\begin{array}{l}\text { Patrick } \\
\text { Giraudoux }\end{array}$ & 2013 & $\begin{array}{l}\text { Tibetan } \\
\text { plateau }\end{array}$ & $A E$ & $\begin{array}{l}\text { Cross- } \\
\text { sectional }\end{array}$ & 15614 & 577 & $1,2,7$ & 5 \\
\hline 13 & $\begin{array}{l}\text { Kechong } \\
\text { Bai }\end{array}$ & 2013 & Xinjiang & CE & $\begin{array}{l}\text { Cross- } \\
\text { sectional }\end{array}$ & 869 & 11 & 1 & 4 \\
\hline 14 & $\begin{array}{l}\text { Guizhi } \\
\text { Wang }\end{array}$ & 2009 & Xinjiang & CE & $\begin{array}{l}\text { Case- } \\
\text { control }\end{array}$ & 5037 & 141 & $2,3,7$ & 6 \\
\hline 15 & $\begin{array}{l}\text { Junxia } \\
\text { Yuan }\end{array}$ & 2011 & Gansu & CE & $\begin{array}{l}\text { Case- } \\
\text { control }\end{array}$ & 75 & 25 & 3,8 & 6 \\
\hline \multirow[t]{2}{*}{16} & \multirow{2}{*}{$\begin{array}{l}\text { Yunling } \\
\text { Feng }\end{array}$} & \multirow[t]{2}{*}{2011} & \multirow[t]{2}{*}{ Ningxia } & $A E$ & \multirow{2}{*}{$\begin{array}{l}\text { Cross- } \\
\text { sectional }\end{array}$} & \multirow[t]{2}{*}{6039} & \multirow[t]{2}{*}{89} & 1 & \multirow[t]{2}{*}{5} \\
\hline & & & & CE & & & & 1 & \\
\hline \multirow[t]{2}{*}{17} & \multirow[t]{2}{*}{ Xianglin Wu } & \multirow[t]{2}{*}{2010} & \multirow[t]{2}{*}{ Ningxia } & $A E$ & \multirow{2}{*}{$\begin{array}{l}\text { Cross- } \\
\text { sectional }\end{array}$} & \multirow[t]{2}{*}{3196} & \multirow[t]{2}{*}{72} & $1,3,5$ & \multirow[t]{2}{*}{5} \\
\hline & & & & CE & & & & $1,3,5,8$ & \\
\hline 18 & Li Zhong & 2009 & Xinjiang & CE & $\begin{array}{l}\text { Cross- } \\
\text { sectional }\end{array}$ & 3691 & 56 & 1,7 & 5 \\
\hline 19 & Li Li & 2008 & Ningxia & CE & $\begin{array}{l}\text { Case- } \\
\text { control }\end{array}$ & 303 & 101 & $3,9,13$ & 7 \\
\hline 20 & Jv Yang & 2008 & Ningxia & CE & $\begin{array}{l}\text { Case- } \\
\text { control }\end{array}$ & 387 & 129 & $8,9,13$ & 6 \\
\hline \multirow[t]{2}{*}{21} & \multirow{2}{*}{$\begin{array}{l}\text { Yu Rong } \\
\text { Yang }\end{array}$} & \multirow[t]{2}{*}{2006} & \multirow[t]{2}{*}{ Ningxia } & $A E$ & \multirow{2}{*}{$\begin{array}{l}\text { Cross- } \\
\text { sectional }\end{array}$} & 4773 & 96 & 1 & 5 \\
\hline & & & & CE & & & 75 & 1,9 & \\
\hline 22 & Qian Wang & 2006 & Sichuan & $A E$ & $\begin{array}{l}\text { Cross- } \\
\text { sectional }\end{array}$ & 7138 & 223 & $1,2,3,4,5,6,7$ & 5 \\
\hline 23 & P. M. & 2003 & Qinghai & $A E$ & Cross- & 3703 & 31 & $1,2,5,6,7,8,9,10$ & 6 \\
\hline & & & & CE & & & 243 & $1,2,5,7,8,9,10$ & \\
\hline 24 & Qian Wang & 2001 & Sichuan & $A E$ & $\begin{array}{l}\text { Cross- } \\
\text { sectional }\end{array}$ & 1858 & 43 & $1,3,4,5,6$ & 4 \\
\hline
\end{tabular}




\begin{tabular}{|c|c|c|c|c|c|c|c|c|c|}
\hline & & & & CE & & & 65 & 1,3 & \\
\hline 25 & $\begin{array}{l}\text { Xianhong } \\
\text { Wu }\end{array}$ & 2001 & Qinghai & CE & $\begin{array}{l}\text { Cross- } \\
\text { sectional }\end{array}$ & 817 & 38 & 1,2 & 4 \\
\hline 26 & P.S. Craig & 2000 & Gansu & $\mathrm{AE}$ & $\begin{array}{l}\text { Cross- } \\
\text { sectional }\end{array}$ & 2482 & 84 & 3,4 & 5 \\
\hline
\end{tabular}

*1. Sex (Female/Male); 2. Ethnicity (Tibetan/Han); 3. Dog ownership; 4. Touched fox skin; 5. Not washing hands before meals; 6. Playing with dogs; 7. Herder status; 8 . Feeding viscera to dogs; 9 . Drinking nonboiled water; 10 . Presence of stray dogs; 11 . Number of household dog (with each addition); 12. Nomadism; 13. Eating raw vegetables

AE: alveolaris echinococcosis; CE: cystic echinococcosis.

Table 2 Result of echinococcosis risk factors meta-analysis

\begin{tabular}{|c|c|c|c|c|c|c|c|c|c|c|c|}
\hline \multirow[t]{2}{*}{ Risk factor } & \multirow{2}{*}{$\begin{array}{l}\text { Number } \\
\text { of } \\
\text { studies } \\
\text { included }\end{array}$} & \multirow[t]{2}{*}{$\begin{array}{l}\text { Type of } \\
\text { echinococcosis }\end{array}$} & \multirow[t]{2}{*}{$\begin{array}{l}\text { Sample } \\
\text { size }\end{array}$} & \multirow[t]{2}{*}{$\begin{array}{l}\text { positive } \\
\text { cases }\end{array}$} & \multicolumn{3}{|c|}{ Test of heterogeneity } & \multirow[t]{2}{*}{ OR } & \multirow[t]{2}{*}{$\begin{array}{l}95 \% \\
\mathrm{Cl}\end{array}$} & \multicolumn{2}{|c|}{$\begin{array}{l}\text { Test of overall } \\
\text { effect }\end{array}$} \\
\hline & & & & & Q & $\mathrm{P}$ & $\begin{array}{l}1^{2} \\
(\%)\end{array}$ & & & z & $\begin{array}{l}\mathrm{P}- \\
\text { value }\end{array}$ \\
\hline Sex(Female/Male) & 8 & $\mathrm{AE}$ & 51781 & 1479 & 10.59 & 0.158 & 33.9 & 1.45 & $\begin{array}{l}1.26- \\
1.66\end{array}$ & 6.73 & $<0.001$ \\
\hline Ethnicity(Tibetan/Han) & 3 & $\mathrm{AE}$ & 26455 & 831 & 1.92 & 0.382 & 0 & 2.94 & $\begin{array}{l}1.81- \\
4.75\end{array}$ & 4.38 & $<0.001$ \\
\hline Dog ownership & 4 & $\mathrm{AE}$ & 14674 & 422 & 8.15 & 0.043 & 63.2 & 1.52 & $\begin{array}{l}0.96- \\
2.39\end{array}$ & 1.78 & 0.075 \\
\hline Playing with dogs & 3 & $\mathrm{AE}$ & 12699 & 297 & 24.44 & $<0.001$ & 91.8 & 1.72 & $\begin{array}{l}0.45- \\
6.52\end{array}$ & 0.8 & 0.424 \\
\hline Touch fox skin & 3 & $\mathrm{AE}$ & 11478 & 350 & 4.82 & 0.090 & 58.5 & 1.19 & $\begin{array}{l}0.70- \\
2.02\end{array}$ & 0.64 & 0.523 \\
\hline $\begin{array}{l}\text { Not washing hands } \\
\text { before meals }\end{array}$ & 4 & $\mathrm{AE}$ & 15895 & 369 & 17.49 & 0.001 & 82.8 & 2.40 & $\begin{array}{l}1.34- \\
4.28\end{array}$ & 2.96 & 0.003 \\
\hline Herder status & 3 & $\mathrm{AE}$ & 26455 & 831 & 2.17 & 0.337 & 8 & 2.66 & $\begin{array}{l}2.25- \\
3.14\end{array}$ & 12.63 & $<0.001$ \\
\hline Sex(Female/Male) & 14 & CE & 139367 & 3450 & 89.4 & $<0.001$ & 85.5 & 1.30 & $\begin{array}{l}1.11- \\
1.53\end{array}$ & 3.27 & 0.001 \\
\hline Ethnicity(Tibetan/Han) & 4 & CE & 33002 & 1470 & 14.44 & 0.002 & 79.2 & 3.18 & $\begin{array}{l}1.55- \\
6.52\end{array}$ & 3.16 & 0.002 \\
\hline Dog ownership & 6 & CE & 10847 & 593 & 9.88 & 0.079 & 49.4 & 1.54 & $\begin{array}{l}1.09- \\
2.17\end{array}$ & 2.46 & 0.014 \\
\hline $\begin{array}{l}\text { Not washing hands } \\
\text { before meals }\end{array}$ & 5 & CE & 14948 & 659 & 21.44 & $<0.001$ & 81.3 & 2.05 & $\begin{array}{l}1.35- \\
3.10\end{array}$ & 3.39 & 0.001 \\
\hline Herder status & 7 & CE & 159148 & 3041 & 40.25 & $<0.001$ & 85.1 & 2.19 & $\begin{array}{l}1.67- \\
2.86\end{array}$ & 5.71 & $<0.001$ \\
\hline $\begin{array}{l}\text { Feeding viscera to } \\
\text { dogs }\end{array}$ & 7 & CE & 14524 & 840 & 7.64 & 0.266 & 21.5 & 2.35 & $\begin{array}{l}1.89- \\
2.91\end{array}$ & 7.78 & $<0.001$ \\
\hline $\begin{array}{l}\text { Drinking nonboiled } \\
\text { water }\end{array}$ & 5 & CE & 14979 & 638 & 27.91 & $<0.001$ & 85.7 & 2.47 & $\begin{array}{l}1.36- \\
4.47\end{array}$ & 2.99 & 0.003 \\
\hline Presence of stray dogs & 4 & CE & 11752 & 587 & 6.11 & 0.106 & 50.9 & 1.75 & $\begin{array}{l}1.15- \\
2.65\end{array}$ & 2.64 & 0.008 \\
\hline $\begin{array}{l}\text { Number of household } \\
\text { dog(with each } \\
\text { addition) }\end{array}$ & 3 & CE & 470778 & 33117 & 7.48 & 0.024 & 73.2 & 1.66 & $\begin{array}{l}1.17- \\
2.34\end{array}$ & 2.85 & 0.004 \\
\hline Nomadism & 3 & CE & 2830 & 157 & 4.53 & 0.104 & 55.8 & 2.71 & $\begin{array}{l}1.65- \\
4.47\end{array}$ & 3.92 & $<0.001$ \\
\hline Eating raw vegetables & 3 & CE & 6503 & 320 & 0.84 & 0.658 & 0 & 1.86 & $\begin{array}{l}1.47- \\
2.35\end{array}$ & 5.16 & $<0.001$ \\
\hline
\end{tabular}




\section{Figures}

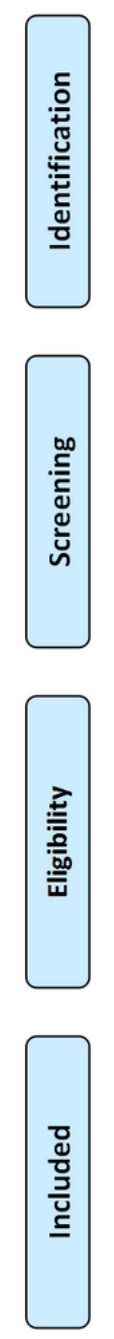

1026 of records identified through database Searching Pubmed $=33$, Embase $=43$, Web of Science $=43$, Cochrane $=0$, CNKI=266, VIP=106, Wanfang=268, SinoMed $=267$.

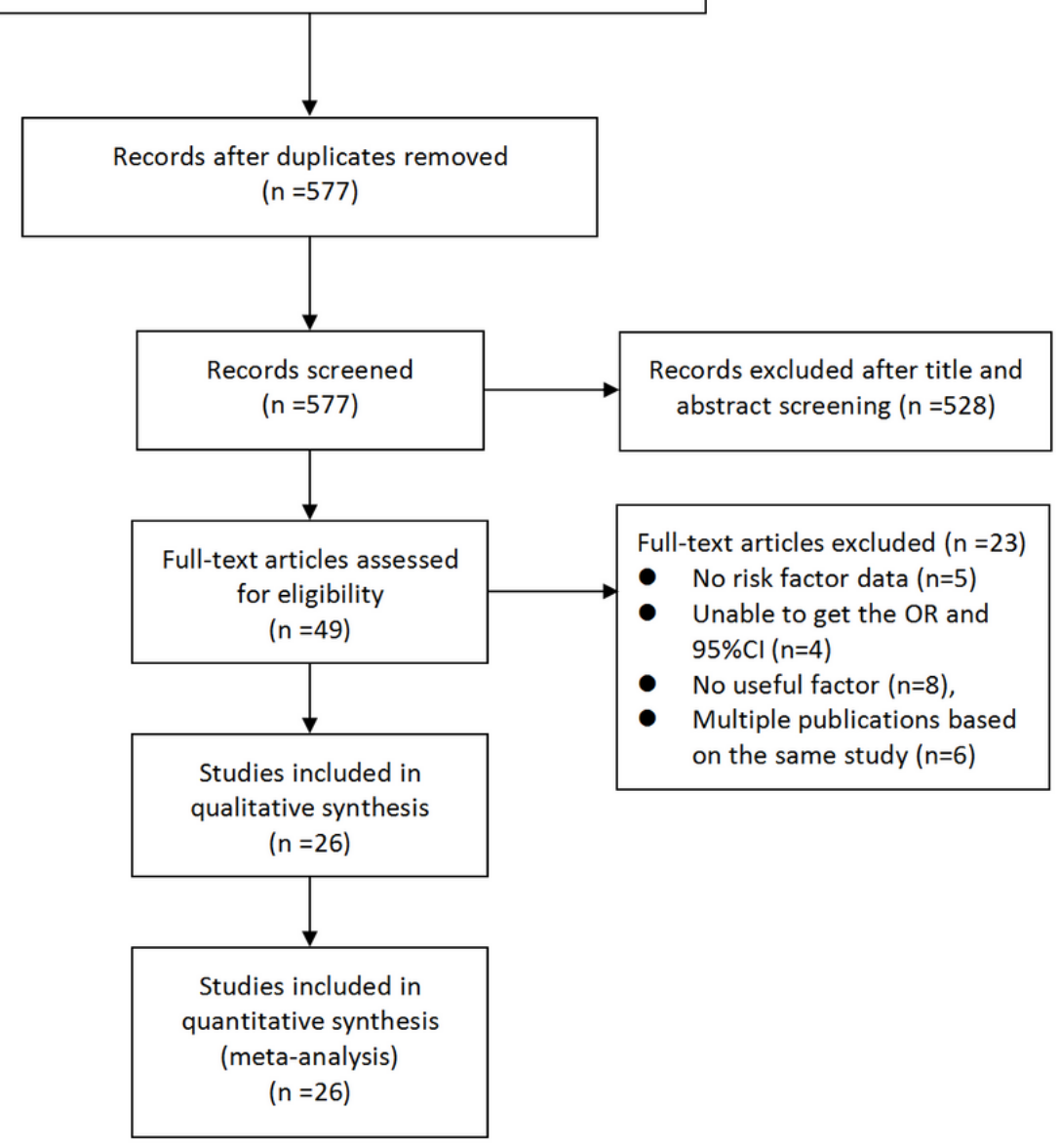

Figure 1

Summary of the literature search and study selection 
A

Study
Kun Li 2017
Xinwei Qi 2015
AiLuo 2014
Yu Rong Yang 2006
P. M. SCHANTZ 2003
Qian Wang 2001
Kechong Bai 2013
Bin Li 2019
Ye He 2017
Xianhong Wu 2001
Xianglin Wu 2010
Li Zhong 2009
Yunling Feng 2011

Random effects model

Heterogeneity $I^{2}=35 \%$
TE seTE

0.450 .6323

$\begin{array}{lll}0.77 & 0.2568\end{array}$

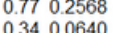

$\begin{array}{lll}0.34 & 0.0640 \\ 0.31 & 0.2567\end{array}$

$\begin{array}{llll}0.31 & 0.2567 \\ 0.58 & 0.1194\end{array}$

$\begin{array}{lll}0.58 & 0.1194 \\ 0.12 & 0.2534\end{array}$

0.120 .2534

$\begin{array}{rrr}-0.82 & 0.6225 \\ 0.31 & 0.0560\end{array}$

$\begin{array}{lll}0.31 & 0.0560 \\ 0.19 & 0.1074\end{array}$

$\begin{array}{llll}0.19 & 0.1074 \\ 0.47 & 0.3211\end{array}$

$\begin{array}{lll}0.47 & 0.3211 \\ 0.12 & 0.2338\end{array}$

$-0.210 .2660$

0.440 .2193

$=0.0104, p=0.10$
Odds Ratio

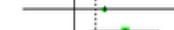

$\begin{array}{rrrr}\vdots & 1.57 & {[0.46 ; 5.44]} & 0.7 \%\end{array}$ $2.15[1.30 ; 3.56] \quad 4.0 \%$ $1.47[1.24,1.60] 21.1 \%$ $1.78[1.41 ; 225]-12.4 \%$ $1.12[0.68,1.84] \quad 4.1 \%$ $1.12[0.68,1.84] \quad 4.1 \%$ $0.44[0.13,1.49] \quad 0.8 \%$ $1.36 \quad[1.22,1.52] \quad 22.6 \%$ 1.22 [0.98, 1.50] $13.9 \%$ $1.60[0.85,3.00] \quad 2.7 \%$ $1.12[0.71,1.78] \quad 4.7 \%$ $0.81[0.48 ; 1.36] \quad 3.8 \%$ $1.55[1.01 ; 2.39] \quad 5.2 \%$ $1.37[1.23 ; 1.53] 100.0 \%$

(1)

B

$\begin{array}{lllll}\text { Study } & \text { TE seTE } & \text { Odds Ratio } & \text { OR } & 95 \%-\mathrm{Cl} \text { Weight }\end{array}$

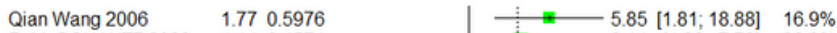

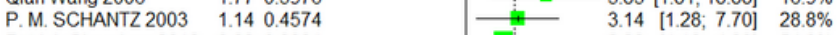
Patrick Giraudoux $2013 \quad 0.830 .3331 \quad 2.28[1.19 ; 4.39] \quad 54.3 \%$

Random effects model

Heterogeneity. $I^{2}=0 \%, \tau^{2}=0, p=0.38$

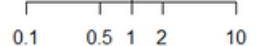

$2.93[1.81 ; 4.75] 100.0 \%$

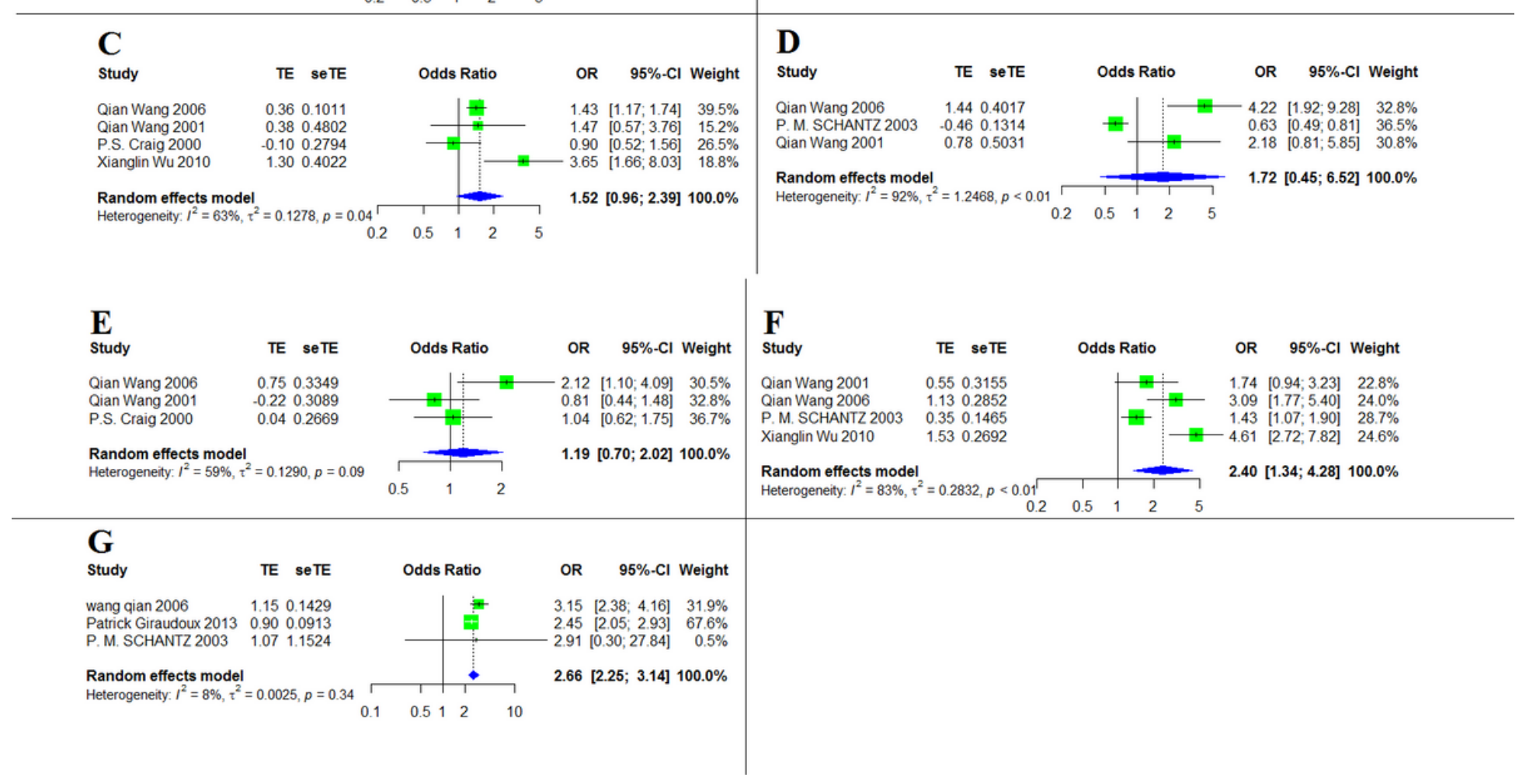

Figure 2

The forest chart of AE factors. A: Sex (Female/Male); B: Ethnicity (Tibetan/Han); C: Dog ownership; D: Playing with dogs; E: Touch fox skin; F: Not washing hands before meals; G: Herder status. 


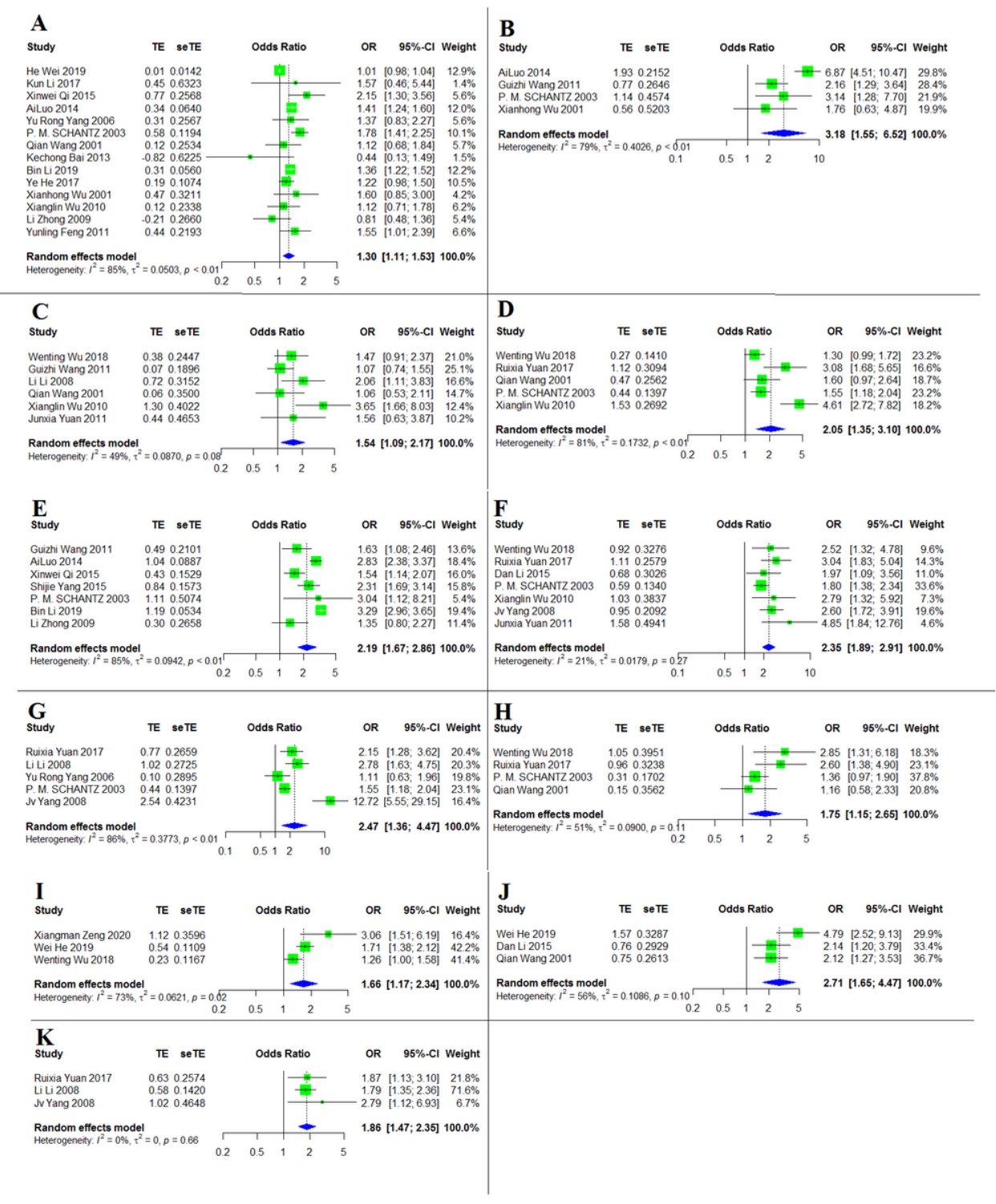

\section{Figure 3}

The forest chart of CE factors. A: Sex (Female/Male); B: Ethnicity (Tibetan/Han); C: Dog ownership; D: Not washing hands before meals; E: Herder status; F: Feeding viscera to dogs; G: Drinking nonboiled water; H: Presence of stray dogs; I: Number of household dog (with each addition); J: Nomadism; K: Eating raw vegetables. 


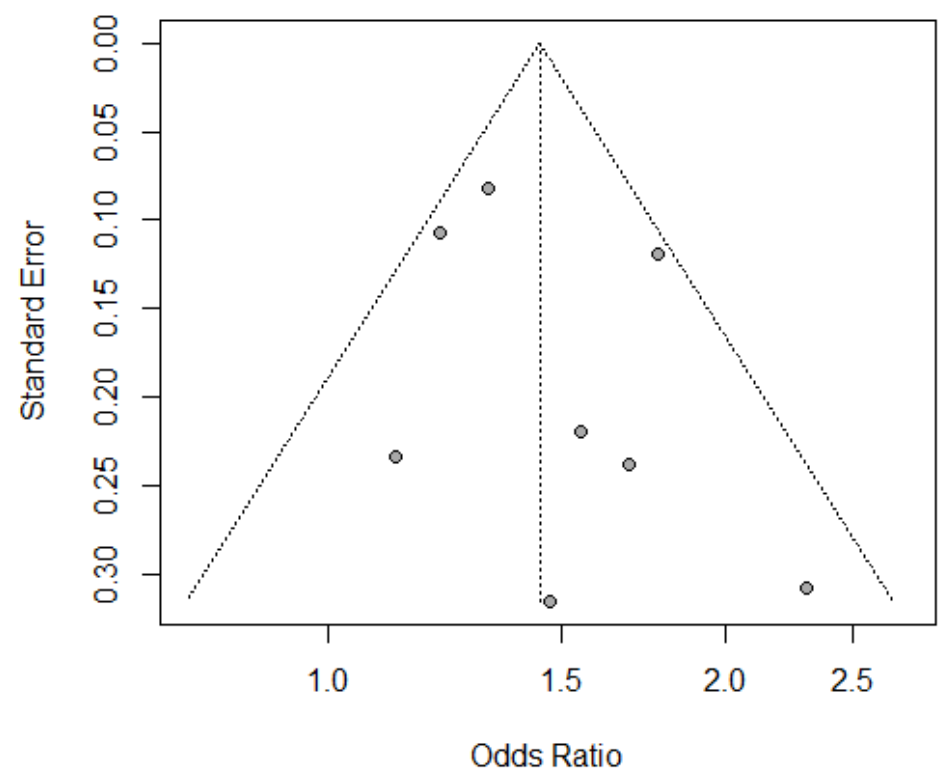

Figure 4

Funnel chart of AE risk factor sex
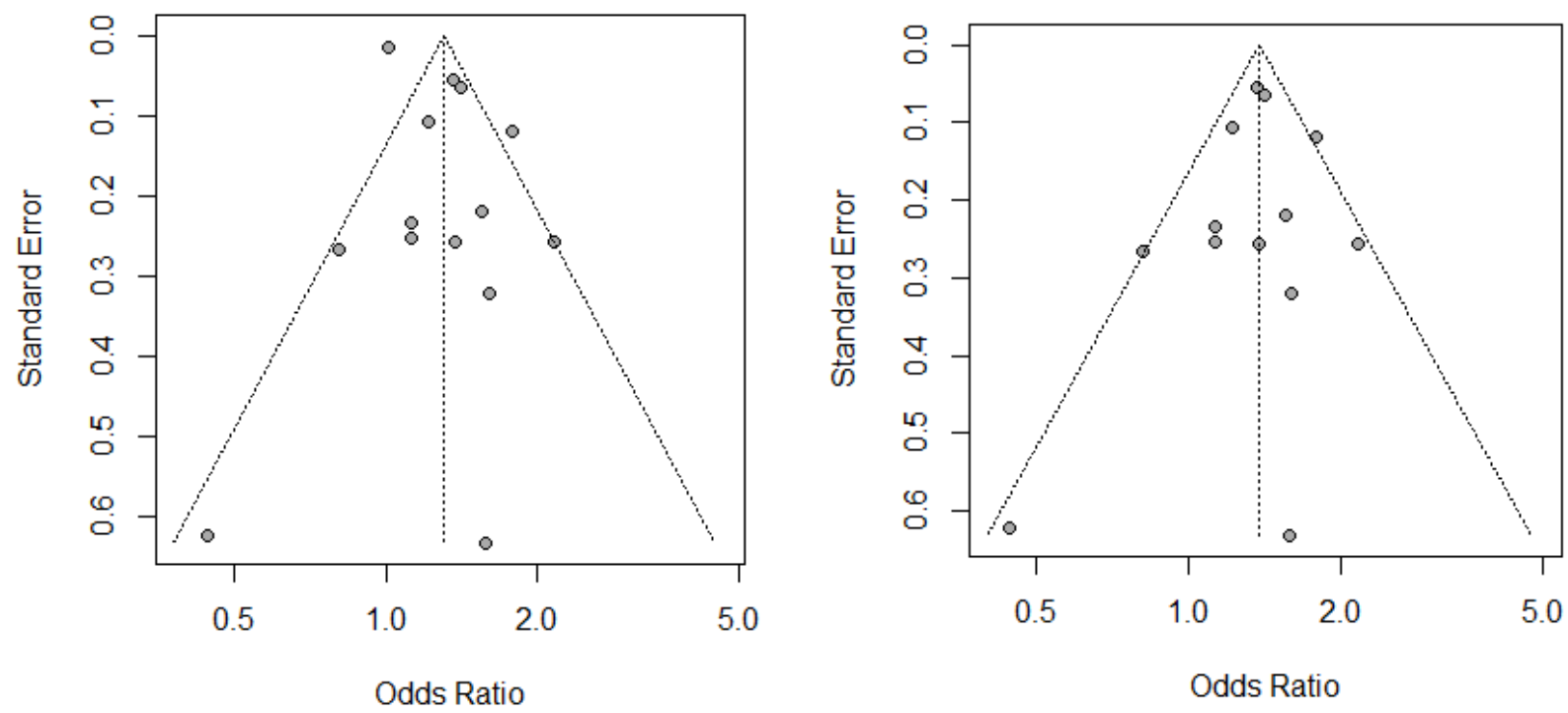

Figure 5

Funnel chart of CE risk factor sex before and after study design subgroup analysis.

\section{Supplementary Files}

This is a list of supplementary files associated with this preprint. Click to download.

- additionalfile1.docx

- graphicalabstract.png 